\title{
Physician Empathy and Listening: Associations with Patient Satisfaction and Autonomy
}

\author{
Kathryn I. Pollak, PhD, Stewart C. Alexander, PhD, James A. Tulsky, MD, \\ Pauline Lyna, MPH, Cynthia J. Coffman, PhD, Rowena J. Dolor, MD, MHS, \\ Pål Gulbrandsen, MD, PhD, and Truls Østbye, MD, PhD
}

Purpose: Motivational Interviewing (MI) is used to help patients change their behaviors. We sought to determine if physician use of specific MI techniques increases patient satisfaction with the physician and perceived autonomy.

Methods: We audio-recorded preventive and chronic care encounters between 40 primary care physicians and 320 of their overweight or obese patients. We coded use of MI techniques (eg, empathy, reflective listening). We assessed patient satisfaction and how much the patient felt the physician supported him or her to change. Generalized estimating equation models with logit links were used to examine associations between MI techniques and patient perceived autonomy and satisfaction.

Results: Patients whose physicians were rated as more empathic had higher rates of high satisfaction than patients whose physicians were less empathic $(29 \%$ vs $11 \% ; P=.004)$. Patients whose physicians made any reflective statements had higher rates of high autonomy support than those whose physicians did not $(46 \%$ vs $30 \% ; P=.006)$.

Conclusions: When physicians used reflective statements, patients were more likely to perceive high autonomy support. When physicians were empathic, patients were more likely to report high satisfaction with the physician. These results suggest that physician training in MI techniques could potentially improve patient perceptions and outcomes. (J Am Board Fam Med 2011;24:665-672.)

Keywords: Counseling, Empathy, Patient Satisfaction, Reflective Listening

Patient-physician communication is a central component of high-quality care. Several studies have shown that quality communication is associated with higher

This article was externally peer reviewed.

Submitted 27 January 2011; revised 6 June 2011; accepted 8 June 2011.

From the Cancer Prevention, Detection, and Control Research Program (KIP, JAT, PL, TØ), the Department of Community and Family Medicine (KIP, TØ), the Department of Medicine (SCA, JAT), and the Department of Biostatistics and Bioinformatics (CJC), Duke University Medical Center, Durham, NC; the Durham Veterans Affairs Medical Center, Center for Health Services Research, Durham, NC (SCA, JAT, CJC, RJD); Health Services and Systems Research, DukeNational University of Singapore Graduate Medical School, Singapore (TØ); and the Akershus University Hospital and University of Oslo, Oslo, Norway (PG).

Funding: This work was supported by grants R01CA114392, R01HL092403, R01DK64986, and R01DK075439. Support was provided by Health Services Research Career Development Award RCD 07-006 from the Department of Veterans Affairs (SCA).

Conflict of interest: none declared.

Corresponding author: Kathryn I. Pollak, 2424 Erwin Road, Suite 602, Durham, NC 27705 (E-mail: Kathryn.pollak@ duke.edu). patient satisfaction and adherence and a lower probability of malpractice suits. ${ }^{1-3}$ Some communication, however, presents challenges for primary care physicians. For instance, physicians report barriers to counseling about weight loss, such as not enough time and fear of embarrassing patients. ${ }^{4,5}$ Further, they rarely see positive effects of their counseling.

An effective counseling style that has been receiving attention for application in primary care settings is motivational interviewing (MI). The main purpose of $\mathrm{MI}$ is to elicit people's internal motivation to change through exploring and resolving ambivalence., When delivered by counselors outside of the primary care encounter, $\mathrm{MI}$ has been found to be effective in changing an array of health-related behaviors. ${ }^{8-11}$ Three studies have shown that when physicians who are counseling patients use MI techniques, such as reflective statements and praise, their patients are more likely to lose weight. ${ }^{12,13}$ By using these MI techniques, physicians partner with patients and show support for their autonomy to make their own 
changes. This, in turn, may lead patients to feel more satisfied and to believe that they can, in fact, make decisions for themselves. ${ }^{14,15}$ However, no one has examined whether these relationships actually occur. In this article, we explore whether physicians' use of MI techniques during weight loss conversations was associated with greater patient satisfaction and perceived autonomy support.

\section{Methods}

\section{Physician Recruitment}

Project CHAT (Communicating Health: Analyzing Talk) was approved by the Duke University Medical Center institutional review board. Methods are described in detail elsewhere. ${ }^{12}$ Primary care physicians $(n=40)$ from community-based practices were told the study would examine how they address preventive health. Participating physicians gave written consent, completed a baseline questionnaire to assess demographic variables, and provided an electronic signature for generating letters to their patients. Between 11 and 13 patient visits per physician were audio recorded.

\section{Patient Recruitment}

To avoid acute care visits in which weight likely would not be addressed, only patients with appointments that were at least 3 weeks in advance or further out were randomly selected. For these selected patients, a letter signed by the patient's physician introduced the study to patients as examining how physicians address preventive health with patients. Included in the letter was a toll-free number to refuse contact. One week later, patients were called to review eligibility and administer the baseline questionnaire to assess demographics. Eligible patients were at least 18 years of age, English speaking, cognitively able to provide consent, not pregnant, and had a body mass index $(\mathrm{BMI})>25$. Immediately after the encounter, patients completed a questionnaire that asked them to rate their physician's communication (see Measures, below). Data from patients and physicians who discussed weight are included in this article (320 of $461 \mathrm{pa}-$ tient-physician encounters). Data collection occurred between December 2006 and June 2008.

\section{Coding Audio Recordings: Motivational Interviewing}

Two independent coders, who had received 30 hours of training, assessed MI using the Motiva- tional Interview Treatment Integrity scale, ${ }^{16}$ a reliable and valid assessment of MI techniques. ${ }^{17,18}$ When conflicts arose, they discussed and agreed on a code. Interrater reliability was assessed using intraclass correlation coefficients (ICCs) to take into account the differences in ratings for individual segments, along with the correlation between raters. ${ }^{19}$ Shrout ${ }^{20}$ proposed the following benchmarks for the interpretation of interrater reliability coefficients: 0.00 to 0.10 (virtually none), 0.11 to 0.40 (slight), 0.41 to 0.60 (fair), 0.61 to 0.80 (moderate), and 0.81 to 1.0 (substantial). They assessed global ratings of "empathy" ( 1 to 5 scale; ICC $=0.70$ ), which was defined as the physician showing evidence of understanding of patient's point of view. They also coded "MI spirit" ( 1 to 5 scale; ICC = 0.81 , which included three components: (1) evocation (eliciting patients' own reasons for change), (2) collaboration (acting as partners), and (3) autonomy (conveying that change comes only from patients).

Coders also identified six physician behaviors, including (1) closed questions (yes/no; ICC = 0.82 ), (2) open questions (ICC $=0.78$ ), (3) simple reflections (conveys understanding but adds no new meaning; ICC $=0.45$ ), (4) complex reflections (conveys understanding and adds substantial meaning; ICC = 1.0), (5) MI-consistent behaviors (asking permission, affirming, providing supportive statements, and emphasizing control; ICC $=0.70$ ), and MI-inconsistent behaviors (advising without permission, confronting, and directing; ICC = $0.77)$.

\section{Patient Satisfaction}

Patients were asked nine questions to assess their satisfaction with the visit. ${ }^{21}$ Sample items include, "In terms of satisfaction, how would you rate each of the following:" the technical skills (thoroughness, carefulness, competence) of the physician you saw and time spent with the physician you saw $(1=$ poor, 2 = fair, $3=$ good, $4=$ very good, and $5=$ excellent; $\alpha=0.79$ ). To be consistent with previous reports of this measure, the patient satisfaction scale was dichotomized (5, excellent vs 1 to 4 , not excellent $)^{21,22}$

\section{Patient Autonomy Support}

Patients were asked 15 questions to assess how well physicians supported their autonomy. ${ }^{23}$ Sample items read, "I feel that my physician has provided 
me choices and options" and "I feel understood by my physician" $(1=$ strongly disagree to $5=$ strongly agree; $\alpha=0.94)$. Because of the skewed distribution $(38 \%$ had the maximum score of 75 ; median score, 73), the outcome for autonomy support was dichotomized as the highest perceived autonomy (score of 75) versus not the highest perceived autonomy (score $<75){ }^{23}$

\section{Primary Outcome Measure, Predictor Variables, and Covariates}

The effect of the following MI techniques on patient satisfaction and autonomy support were examined: (1) MI spirit (score >1); (2) empathy (score $>1$ ); (3) open questions (any open questions); (4) reflections (any simple and/or complex reflections); and (5) MI-consistent and MI-inconsistent behaviors).

Patient-level covariates included sex; age; race; comorbidities (diabetes, hypertension, arthritis, and hyperlipidemia); high school education; economic security (enough money to pay monthly bills); weight-designation of overweight (BMI, 25$29.9 \mathrm{~kg} / \mathrm{m}^{2}$ ) or obese (BMI $\left.\geq 30 \mathrm{~kg} / \mathrm{m}^{2}\right)$; actively trying to lose weight; motivated to lose weight; comfortable discussing weight; and confident about losing weight.

\section{Analyses}

All analyses were performed using SAS software version 9.2 (SAS Institute, Inc., Cary, NC). For raw scores of patient satisfaction and autonomy support, an ICC was calculated to evaluate similarity and independence among patients by examining patient satisfaction (ICC $=0.11$ ) and perceived autonomy (ICC $=0.09$ ) by physician. ${ }^{24} \mathrm{We}$ also calculated the proportion of encounters per physician in which physicians used each of the MI constructs and the proportion of encounters per physician that had high satisfaction and/or autonomy. Separate models for each of the five MI techniques were fit to examine the association between use of the MI technique with patient satisfaction and autonomy support.

For these models, PROC GENMOD was used to fit a generalized estimating equation model with a logit link $\mathrm{k}^{25}$ adjusting for physician clustering. Because of limited variability in both binary autonomy and satisfaction outcomes, we were limited in the number of variables we could include in our models. ${ }^{26}$ Models for perceived autonomy included covariates that were defined $a$ priori at the patient level (eg, age, sex, race) as described above, and no covariates were included in models for patient satisfaction.

Table 1. Patient and Visit Characteristics for Patients in Weight-Related Discussions* $(n=320)$

\begin{tabular}{|c|c|}
\hline \multicolumn{2}{|l|}{ Patient characteristics } \\
\hline Baseline weight, $\mathrm{kg}$ (mean [SD]) & $93.9(21.2)$ \\
\hline Obese (BMI $\geq 30)$ & $61(194)$ \\
\hline \multicolumn{2}{|l|}{ Race } \\
\hline White/Asian & $61(196)$ \\
\hline African American & $39(124)$ \\
\hline Male & $34(108)$ \\
\hline Age, years (mean $[\mathrm{SD}]$ ) & $58.4(13.3)$ \\
\hline$>$ High school education (missing 1$)^{\dagger}$ & $68(217)$ \\
\hline $\begin{array}{l}\text { Economic security: can pay bills easily } \\
\text { (missing } 11 \text { ) }\end{array}$ & $88(272)$ \\
\hline \multicolumn{2}{|l|}{ Medical history } \\
\hline Diabetes & $33(104)$ \\
\hline Hypertension & $68(217)$ \\
\hline Hyperlipidemia (missing 1) & $56(180)$ \\
\hline Arthritis & $43(136)$ \\
\hline \multicolumn{2}{|l|}{ Weight loss } \\
\hline $\begin{array}{l}\text { Very motivated to lose weight versus } \\
\text { somewhat to not at all }\end{array}$ & $58(184)$ \\
\hline $\begin{array}{l}\text { Very confident can lose weight versus } \\
\text { somewhat to not at all confident }{ }^{\S}\end{array}$ & $36(115)$ \\
\hline $\begin{array}{l}\text { Very comfortable discussing weight with } \\
\text { physician versus somewhat to not at all }\end{array}$ & $73(234)$ \\
\hline Tried to lose weight during past month & $49(158)$ \\
\hline \multicolumn{2}{|l|}{ Visit factors $(\mathrm{n}=320)$} \\
\hline $\begin{array}{l}\text { Total patient-medical personnel in-room time, } \\
\text { min (mean }[\mathrm{SD}])\end{array}$ & $25.9(10.2)$ \\
\hline $\begin{array}{l}\text { Total time spent discussing weight, min } \\
\text { (mean [SD]) }\end{array}$ & $4.2(3.4)$ \\
\hline \multicolumn{2}{|l|}{ Who initiated the weight discussion? } \\
\hline Physician & $36(115)$ \\
\hline Patient & $64(205)$ \\
\hline Weight not discussed & $0(0)$ \\
\hline \multicolumn{2}{|l|}{ Type of encounter (missing 2) } \\
\hline Preventive & $39(123)$ \\
\hline Chronic care & $61(195)$ \\
\hline Explicit weight discussion & $76(242)$ \\
\hline
\end{tabular}

Values provided as \% (n) unless otherwise indicated.

*Patients were considered "counseled" when physicians used motivational interviewing techniques when discussing weight.

${ }^{\dagger}$ Missing data at baseline (counseled sample).

${ }^{\ddagger}$ Motivation to lose weight/address weight $(1=$ not at all, $7=$ very much).

${ }^{\$}$ Self-efficacy to lose weight/address weight $(1=$ not at all confident, $5=$ very confident).

"Comfort discussing weight $(1=$ not at all comfortable, 5 = very comfortable).

BMI, body mass index. 


\section{Results}

\section{Sample Characteristics}

The sample of patients was predominantly white, female, and highly educated (Table 1). Mean age of patients was 59.8 years. Patients had high levels of chronic disease, including hypertension, hyperlipidemia, and diabetes. They were somewhat motivated to lose weight and were moderately confident they could lose weight. Many physicians were white and women. The mean age of physicians was 47.3 years. Physicians were highly confident they could address weight with patients but also reported many barriers that would inhibit adequate discussions. Patients initiated the weight-related discussions $64 \%$ of time.

\section{Techniques and Satisfaction and Autonomy Outcomes}

Physicians had low use of MI spirit and empathy overall, but their use of empathy was variable. Physicians who were rated as empathic in at least one of the encounters were rated as empathic in less than $50 \%$ of all their encounters. Physicians used open questions or reflections in only $30 \%$ to $40 \%$ of their encounters (see Figure 1). There was a wide range of use of any MI-consistent behaviors. The percentage of physician encounters with any MI-inconsistent behaviors ranged from $40 \%$ to $100 \%$ (ie, some physicians used the behaviors in all of their encounters).

Few patients rated their physicians as excellent (11\%). No physician had more than $60 \%$ of patient

Figure 1. Recruitment/participant flow. *Because there were many appointments from which to select, we assigned each appointment a random number and randomly selected which appointments to attempt to audio record.

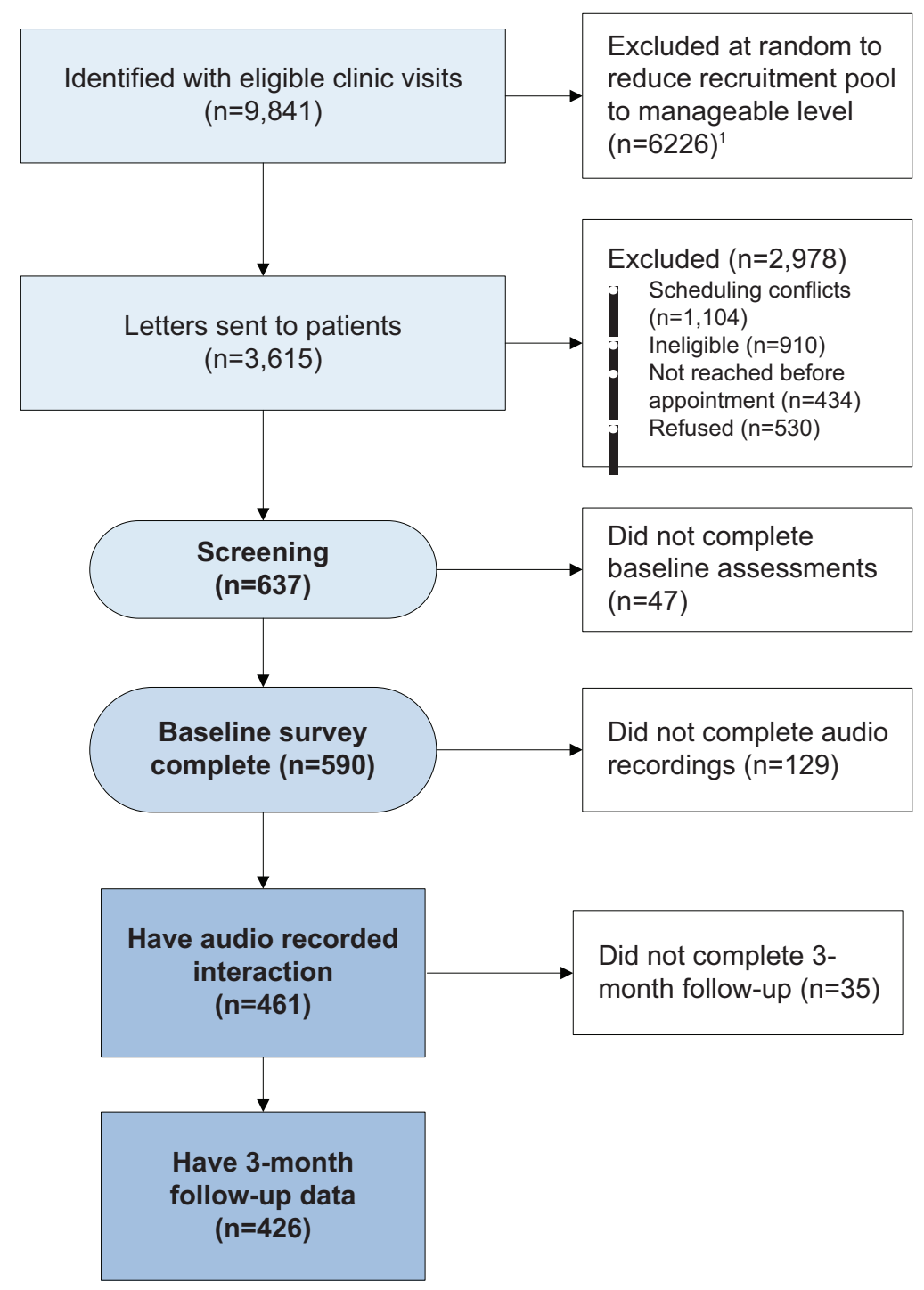


encounters rated as excellent (see Figure 2). Fewer than half of patients (38\%) felt high support for patient autonomy. For physicians, there was a wide range in the percentage of the 11 to 13 encounters in which patients rated the physician as high support for autonomy ( $0 \%$ to $86 \%$; Figure 2$)$.

\section{Relationship of Patient Factors and Patient Perceptions}

Of all the patient covariates, only patient confidence and comfort were related to autonomy support. Patients who were more confident they could lose weight were more likely to report high autonomy support than patients who were less confident (50\% vs $32 \% ; P=.003$; Table 2 ). The same was true for patient comfort level; patients who were more comfortable discussing weight were more likely to report high autonomy support than patients who were less comfortable (44\% vs $21 \% ; P=$ $.002)$.

\section{Relationship between MI Techniques and Patient Perceptions}

In models for patient satisfaction, patients whose physicians were rated higher in empathy (empathy $>1$ ) were more likely to report high satisfaction than patients whose physicians were rated as lower in empathy ( $27 \%$ vs $11 \%$ were very satisfied for empathy $>1$ and empathy $=1$, respectively; Table 3 ). In adjusted analyses, patients in encounters in which physicians made reflective statements had a higher rate of autonomy support than those whose physicians did not (46\% vs 30\% felt high autonomy support for any reflections compared with no reflections; $P=.006$ ). No other relationships were found between MI scores and satisfaction and autonomy support.

\section{Discussion}

There are two main findings in our study. First, despite low overall use of MI techniques, when physicians were more empathic, patients were more satisfied; when physicians used reflective statements, a higher proportion of patients felt high autonomy support. Second, patients' confidence in their ability to lose weight and their comfort discussing weight loss were related to satisfaction and autonomy support.

Physician behavior was related to patients' ratings of satisfaction and perceived autonomy. When physicians were rated as more empathic by independent coders, patients reported a higher rate of "excellent" satisfaction than when physicians were rated as less empathic. Because empathy is defined as physicians understanding patients' perspectives, this might make patients feel more understood, and thus more satisfied. In our previous work, empathy in patient-physician encounters was associated with patient behavior change. ${ }^{10,27}$ Furthermore, another study showed that when physicians expressed com-

Figure 2. Proportion of motivational interviewing (MI) techniques during physician encounters.

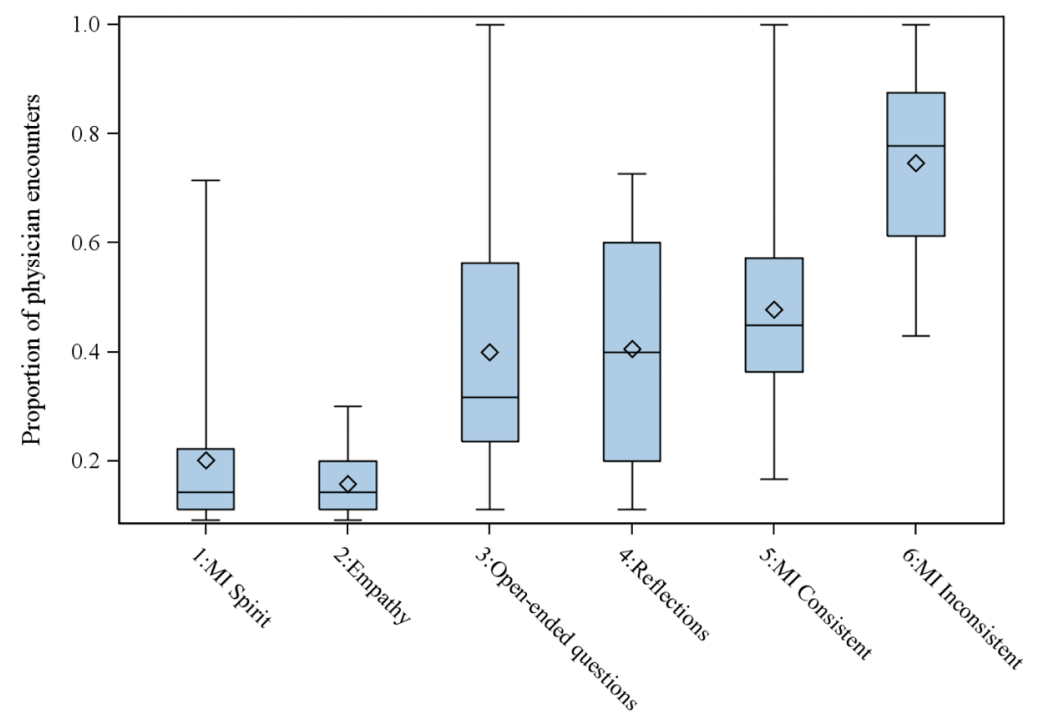

MI contruct 
Table 2. Patient Characteristics and Satisfaction and Autonomy Support

\begin{tabular}{|c|c|c|c|}
\hline Patient Characteristics & Total (n) & Excellent Satisfaction & High Perceived Autonomy Support \\
\hline \multicolumn{4}{|l|}{ Weight } \\
\hline Obese $(\mathrm{BMI} \geq 30)$ & 194 & $11(22)$ & $36(69)$ \\
\hline Not obese $(\mathrm{BMI}<30)$ & 126 & $13(16)$ & $42(53)$ \\
\hline \multicolumn{4}{|l|}{ Race } \\
\hline White/Asian & 196 & $12(23)$ & $38(74)$ \\
\hline African American & 124 & $12(15)$ & $39(48)$ \\
\hline \multicolumn{4}{|l|}{ Sex } \\
\hline Male & 108 & $8(9)$ & $32(35)$ \\
\hline Female & 212 & $14(29)$ & $41(87)$ \\
\hline Age, years* (mean $[\mathrm{SD}]$ ) & 320 & $55.4(13.1)$ & $59.6(13.2)$ \\
\hline \multicolumn{4}{|l|}{ Education (missing 1) } \\
\hline$>$ High School & 217 & $13(29)$ & $35(76)$ \\
\hline$\leq$ High School & 102 & $9(9)$ & $45(46)$ \\
\hline \multicolumn{4}{|l|}{ Economic security (missing 11) } \\
\hline Cannot pay bills easily & 37 & $14(5)$ & $38(14)$ \\
\hline Can pay bills easily & 272 & $12(32)$ & $38(103)$ \\
\hline \multicolumn{4}{|l|}{ Medical history } \\
\hline Diabetes & 104 & $10(10)$ & $34(35)$ \\
\hline Hypertension & 217 & $11(24)$ & $40(86)$ \\
\hline Hyperlipidemia (missing 1) & 180 & $13(24)$ & $41(73)$ \\
\hline Arthritis & 136 & $11(15)$ & $43(59)$ \\
\hline \multicolumn{4}{|l|}{ Motivated to lose weight } \\
\hline Very motivated & 184 & $15(27)$ & $42(77)$ \\
\hline Somewhat to not at all & 136 & $8(11)$ & $33(45)$ \\
\hline \multicolumn{4}{|l|}{ Confident can lose weight } \\
\hline Very confident & 115 & $17(19)$ & $50(57)$ \\
\hline Somewhat to not at all & 205 & $9(19)$ & $32(65)$ \\
\hline \multicolumn{4}{|c|}{ Comfortable discussing weight with physician } \\
\hline Very comfortable & 234 & $15(35)$ & $44(104)$ \\
\hline Somewhat to not at all & 86 & $4(3)$ & $21(18)$ \\
\hline \multicolumn{4}{|c|}{ Tried to lose weight in past month } \\
\hline Yes & 158 & $11(17)$ & $42(66)$ \\
\hline No & 162 & $13(21)$ & $35(56)$ \\
\hline
\end{tabular}

Values provided as \% (n) unless otherwise indicated.

*Mean (SD) for excellent satisfaction and very high perceived autonomy support.

BMI, body mass index.

passion for as few as 40 seconds, patients felt better and less anxious. ${ }^{28}$

When physicians made reflective statements, patients perceived the highest level of autonomy support. One of the main purposes of reflective statements is to share the "conversational floor." When physicians make reflections rather than ask questions, they let patients direct the conversation more than when they only ask questions. An example is if the physician asks, "So, you are disappointed you did not lose weight?" The patient can answer, "Yes," and then the physician is expected to lead the conversation again. In contrast, if the physician says, "It really can be hard to lose weight," the patient is then expected to comment on that statement rather than answer a yes/no question. The patient likely will talk about how hard it has been and possibly about his or her reasons for wanting to lose weight. This might make the patient feel more empowered, more of a partner, and more autonomous than when the physician just asked questions.

Differences in autonomy support were related to some patient factors. Patients who were more confident they could lose weight and were more comfortable talking about weight were more likely to feel that physicians fully supported their autonomy 
Table 3. Physician Communication and Satisfaction and Perceived Autonomy Support

\begin{tabular}{|c|c|c|c|c|}
\hline Model & Total (n) & $\begin{array}{l}\text { Excellent satisfaction* } \\
\quad(\%[95 \% \mathrm{CI}])\end{array}$ & Total (n) & $\begin{array}{l}\text { High perceived autonomy support } \\
\qquad(\%[95 \% \text { CI }])\end{array}$ \\
\hline \multicolumn{5}{|l|}{ MI spirit } \\
\hline$>1$ & 37 & $9(3-23)$ & 36 & $28(15-46)$ \\
\hline 1 & 283 & $12(8-17)$ & 272 & $37(30-43)$ \\
\hline \multicolumn{5}{|l|}{ Empathy } \\
\hline$>1$ & 18 & $27(14-48)$ & 17 & $48(29-68)$ \\
\hline 1 & 302 & $11(8-15)$ & 291 & $35(29-42)$ \\
\hline \multicolumn{5}{|l|}{ Reflections } \\
\hline Yes & 122 & $9(5-15)$ & 118 & $46(36-57)$ \\
\hline No & 198 & $14(10-20)$ & 190 & $30(24-37)$ \\
\hline \multicolumn{5}{|l|}{ Open questions } \\
\hline Yes & 121 & $10(5-19)$ & 115 & $38(26-50)$ \\
\hline No & 199 & $13(9-19)$ & 193 & $35(28-42)$ \\
\hline \multicolumn{5}{|l|}{ MI behaviors } \\
\hline Any MI adherent & 157 & $11(7-16)$ & 152 & $34(26-42)$ \\
\hline No MI adherent & 163 & $13(8-20)$ & 156 & $38(30-47)$ \\
\hline Any MI nonadherent & 263 & $11(7-16)$ & 256 & $37(30-44)$ \\
\hline No MI nonadherent & 57 & $16(8-30)$ & 52 & $31(21-43)$ \\
\hline
\end{tabular}

MI, motivational interviewing.

Bold indicates statistical significance.

than patients who were less confident and less comfortable. It could be that confident and comfortable patients presented themselves to physicians as more independent; physicians then read these cues and treated them as more independent. It also could be that, regardless of physician behavior, patients who were more confident and comfortable viewed their physician as treating them autonomously.

These results are limited by a moderately high refusal rate among patients, which limits generalizability. Also, the low variability in the outcomes limited some of the analyses. Finally, these analyses were conducted with well-educated overweight and obese patients discussing weight, which might not generalize to other populations; however, with more than $60 \%$ of Americans being overweight or obese, the results should be generalizable to a large proportion of overweight and obese Americans. One strength is that neither patients nor physicians knew the study was about weight or specifically about using MI techniques during weight loss counseling. Finally, we used a large dataset of typical primary care patients.

\section{Conclusion}

In this sample of overweight and obese primary care patients, physician use of MI techniques improves both outcomes and important patient perceptions. Increasing physician empathy and number of reflective statements could improve the clinical encounter and patients' adherence to recommendations.

\section{References}

1. Michie S, Miles J, Weinman J. Patient-centeredness in chronic illness: what is it and does it matter? Patient Educ Couns 2003;51:197-206.

2. Stewart MA. Effective physician-patient communication and health outcomes: a review. Can Med Assoc J 1995;152:1423-33.

3. Levinson W, Roter DL, Mullooly JP, Dull VT, Frankel RM. Physician-patient communication. The relationship with malpractice claims among primary care physicians and surgeons. JAMA 1997;277:553-9.

4. Forman-Hoffman V, Little A, Wahls T. Barriers to obesity management: a pilot study of primary care clinicians. BMC Fam Pract 2006;7:35.

5. Alexander SC, Ostbye T, Pollak KI, Gradison M, Bastian LA, Brouwer RJ. Physicians' beliefs about discussing obesity: results from focus groups. Am J Health Promot 2007;21:498-500.

6. Miller WR, Rollnick S. Motivational Interviewing: Preparing People for Change. 2nd ed. New York, NY: Guilford Press; 2002.

7. Emmons KM, Rollnick S. Motivational interviewing in health care settings: opportunities and limitations. Am J Prev Med 2001;20:68-74. 
8. Galuska DA, Will JC, Serdula MK, Ford ES. Are health care professionals advising obese patients to lose weight? JAMA 1999;282:1576-8.

9. Rodondi N, Humair J-P, Ghali WA, et al. Counseling overweight and obese patients in primary care: a prospective cohort study. Eur J Cardiovasc Prev Rehabil 2006;13:222-8.

10. Pollak KI, Ostbye T, Alexander SC, et al. Empathy goes a long way in weight loss discussions. J Fam Pract 2007;56:1031-6.

11. Loureiro ML, Nayga RM Jr. Obesity, weight loss, and physician's advice. Soc Sci Med 2006;62:2458-68.

12. Pollak KI, Alexander SC, Coffman CJ, et al. Physician communication techniques and weight loss in adults: Project CHAT. Am J Prev Med 2010;39: 321-8.

13. Schwartz RP, Hamre R, Dietz WH, et al. Officebased motivational interviewing to prevent childhood obesity: a feasibility study. Arch Pediatr Adolesc Med 2007;161:495-501.

14. Markland D, Ryan RM, Tobin VJ, Rollnick S. Motivational interviewing and self-determination theory. J Soc Clin Psychol 2005;24:811-31.

15. Vansteenkiste M, Sheldon KM. There's nothing more practical than a good theory: integrating motivational interviewing and self-determination theory. Br J Clin Psychol 2006;45:63-82.

16. Moyers TB, Martin T, Manuel JK, Hendrickson SM, Miller WR. Assessing competence in the use of motivational interviewing. J Subst Abuse Treat 2005; 28:19-26.

17. Thyrian JR, Freyer-Adam J, Hannover W, et al. Adherence to the principles of Motivational Interviewing, clients' characteristics and behavior outcome in a smoking cessation and relapse prevention trial in women postpartum. Addict Behav 2007;32: 2297-303.

18. Pierson HM, Hayes SC, Gifford EV, et al. An examination of the Motivational Interviewing Treat- ment Integrity code. J Subst Abuse Treat 2007;32: 11-7.

19. Shrout PE, Fleiss JL. Intraclass correlations: uses in assessing rater reliability. Psychol Bull 1979;86: 420-8.

20. Shrout PE, Fleiss JL. Intraclass correlations: uses in assessing rater reliability. Psychol Bull 1979;86: 420-8.

21. Rubin HR, Gandek B, Rogers WH, Kosinski M, McHorney CA, Ware JE Jr. Patients' ratings of outpatient visits in different practice settings. Results from the Medical Outcomes Study. JAMA 1993;270: 835-40.

22. Makoul G, Krupat E, Chang CH. Measuring patient views of physician communication skills: development and testing of the Communication Assessment Tool. Patient Educ Couns 2007;67:333-42.

23. Williams GC, Grow VM, Freedman ZR, Ryan RM, Deci EL. Motivational predictors of weight loss and weight-loss maintenance. J Pers Soc Psychol 1996; 70(1):115-26.

24. Streiner DL. Learning how to differ: agreement and reliability statistics in psychiatry. Can J Psychiatry 1995;40:60-6.

25. Diggle PJ, Heagerty P, Liang K-Y, Zeger SL. Analysis of Longitudinal Data. New York: Oxford University Press; 2002.

26. Harrell FE. Regression Modeling Strategies with Applications to Linear Models, Logistic Regression, and Survival Analysis. New York, NY: SpringerVerlag; 2001.

27. Cox ME, Yancy WS Jr, Coffman CJ, et al. Effects of counseling techniques on patients' weight-related attitudes and behaviors in a primary care clinic. Patient Educ Couns 2011 Feb 11. Epub ahead of print.

28. Fogarty LA, Curbow BA, Wingard JR, McDonnell $\mathrm{K}$, Somerfield MR. Can 40 seconds of compassion reduce patient anxiety? J Clin Oncol 1999;17:371-9. 